\title{
MILITÊRE BESKERMING VAN STAATSHOOFDE: AGTERGROND EN HERKOMS
}

\section{Lt kdr E.M. Meyers*}

An Institution such as the State President's Guard, has a long history and goes back to antiquity. Famous examples are the guards of King Xerxes of Persia and of more recent origin, the Swiss guard of the Vatican City. In the modern world these guards are the rule rather than the exception, in most states.

The article below looks into the origin, functions and duties of inter alia the English Guard and the French Guard and the requirements for admission into these units. Also the origin and variations of the uniforms of these guards are dealt with.

The female guards employed by the King of Siam deserve to be mentioned because of their unusualness and the author then proceeds to examine the Swiss Guard of the Vatican City.

This article serves as an introduction to the articles that follow, dealing with the State President's unit in the Republic of South Africa.

Instellings soos die Staatspresidentswag het 'n lang geskiedenis. Die gewoonte van konings en staatshoofde om gewapende lyfwagte aan te hou, is terugvoerbaar tot die antieke tye. Beroemde voorbeelde uit die geskiedenis van sodanige wagte is die "Onsterflikes" van koning Xerxes van Persië en van meer onlangse oorsprong, die Switserse Wag wat vandag nog diens doen in die Vatikaanstad. In die moderne wêreld is sodanige wagte in die meeste state eerder die reël as die uitsondering.

Suid-Afrika was 'n Britse kolonie vir meer as 'n honderd-en-vyftig jaar en dis te verwagte dat ons eie instellings van die Britse kant af sterk beïnvloed is. Gedurende die Anglo-Saksiese tydperk het die Britse koning al 'n lyfwag gehad wat hom moes beskerm. Met die verloop van tyd het die funksie van die wag verbreed tot die verlening van seremoniële luister tydens staatsgeleenthede. Die huidige Staatspresidentswag verskyn steeds in hierdie hoedanigheid.

Alvorens die ontstaan van die Staatspresidentswag in oënskou geneem word, moet daar noodwendig stilgestaan word by die herkoms, gebruike en tradisies van derglike prestige eenhede.

Die Britse en Franse modelle word hier bespreek, aangesien die wordingsfases van hul koningswagte nie net gelyklopend, maar deurentyd kompeterend was. Wagte wat ook onder die soeklig kom, is die spesiale koningswag van die koning van Siam wat net uit vrouekrygers bestaan het asook die Switserse Wag, wat die wêreld se kleinste staat waarvan die Pous die staatshoof is, bewaak.

\section{Die ontstaan van die Engelse Wag}

Die eerste koninklike lyfwag op rekord uit die Engelse verlede is die van Edwin, die koning van Northumberland uit die sewende eeu. Vir etlike jare na die Normandiese oorwinnings is daar geen rekord van 'n permanente lyfwag nie. In die tye toe konings nog hulle leërs persoonlik gelei het, was die lyfwag die afdeling waaroor hulle self bevel gevoer het.

\section{Vorming en naamgewing van 'n Franse Wag}

Die Franse koning Philip II wat van 1180 tot 1223 regeer het, het ook 'n spesiale wag vir die beskerming van sy persoon aangestel. Hierdie mag wat gekies is uit boogskutters van die Franse koning se leër het sowat 200 man getel. Hulle was gewapen met pyl en boog asook met stok of staf en het as die "sergens d'armes" of "Sergens a mace" bekend gestaan. Die Franse Wag, die "Becs de Corby" is in 1474 gevorm. 


\section{THE ORIGIN OF THE MILITARY PROTECTION OF HEADS OF STATE \\ HERKOMS VAN DIE MILITÊRE BESKERMING VAN STAATSHOOFDE}
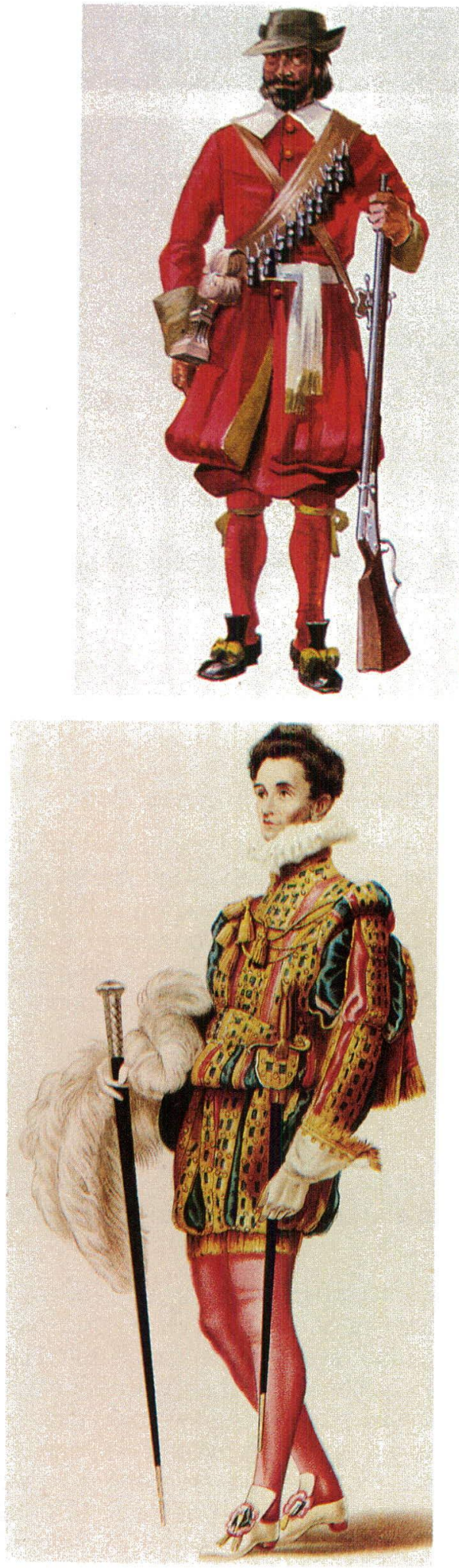

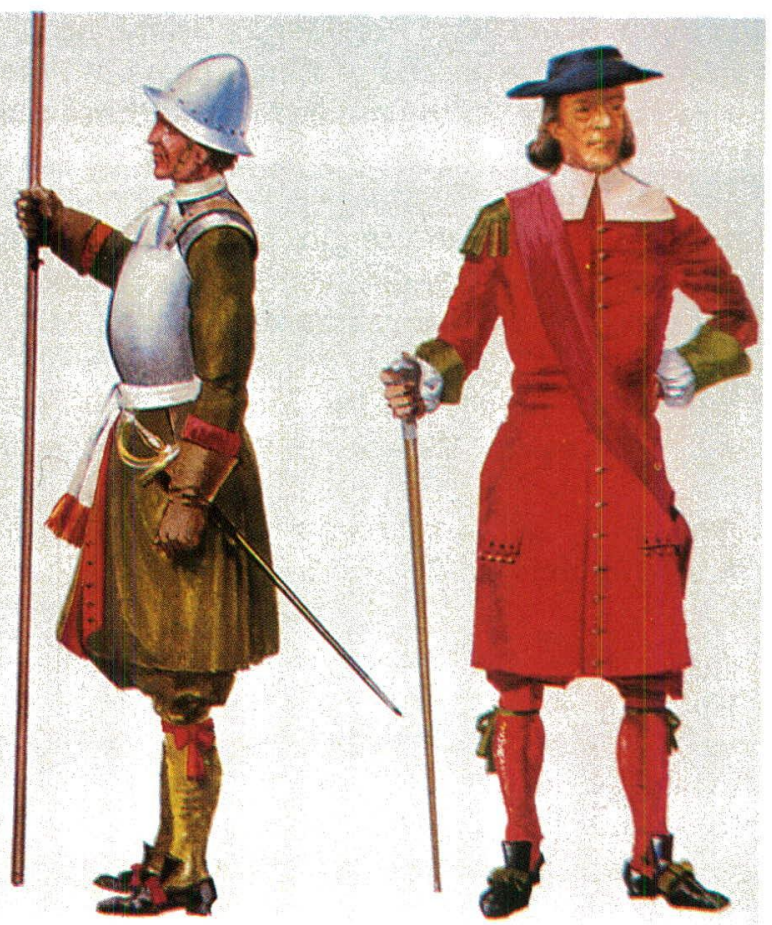

Uniforms van die Britse infanterie in 1670. Van links na regs 'n musketier - 'n piekdraer en 'n tamboermajoor.

Uniforms of the British infantry in 1670. From left to right: a musketeer; a pike bearer and a drum major.

'n Luitenant tydens die kroning van George IV in 1820. Die Middeleeuse glorie het onder hom herleef en Pensioners is op die koning se koste met aanskoulike Tudor uitrustings voorsien. Die uitrusting was bloedrooi met blou invoegsels en bedek met talryke goue knope. Die kostuum is afgerond met rooi sykouse, wit skoene met rooi rose daarop, wit handskoene en 'n swart hoed met rooi en swart vere.

A lieutenant during the coronation of George IV in 1820. During this time, the glory of the Middle Ages was revived and the Pensioners were provided with spectacular Tudor outfits at the King's expense. The outfit was bright red with blue insets and was covered with numerous golden buttons. The costume was finished off with red silk stockings, white shoes decorated with red roses, white gloves and a black hat with red and black feathers. 


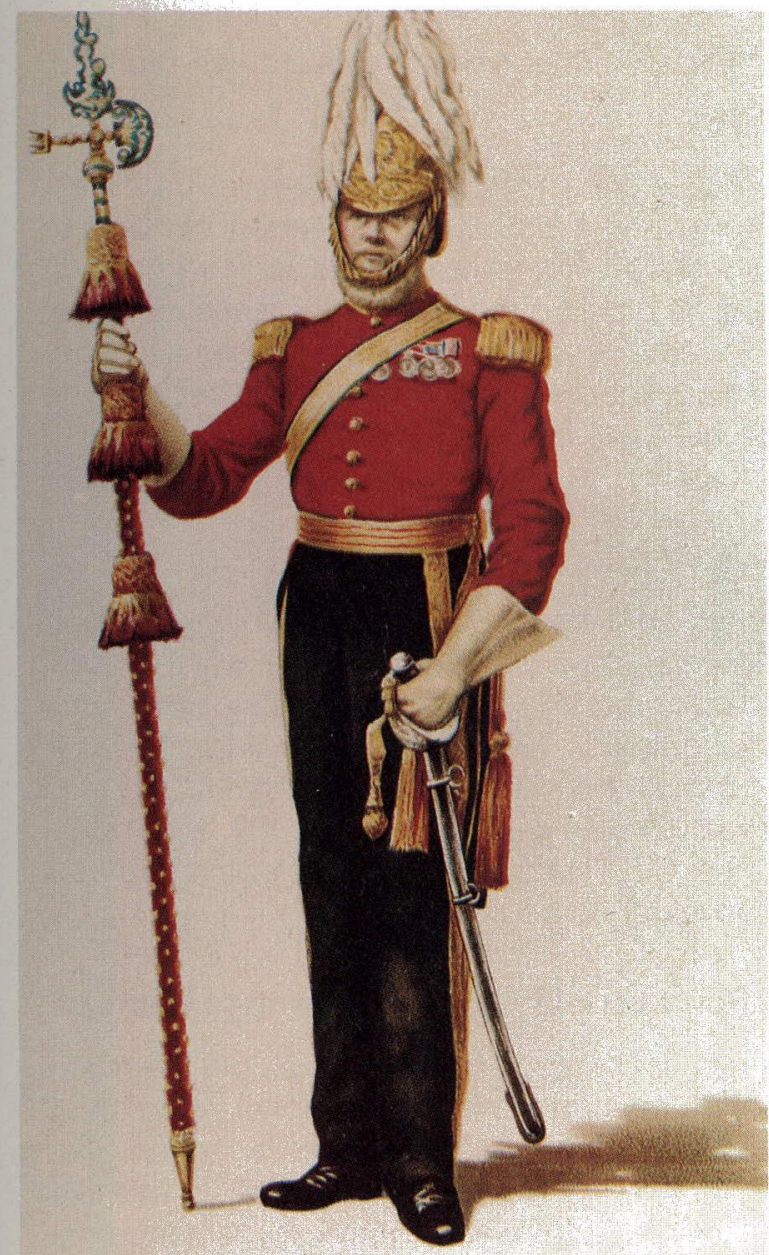

Sedert 1834 die uniform wat deur 'n Gentlemen-at-Arms gedra is. Die Pensioners se naam het verander na

Gentlemen-at-Arms.

The uniform worn by the

Gentlemen-at-Arms since 1834

The name of the Pensioners

was changed to Gentlemen-at-

Arms.

Uniforms van die lyfwagte van die Engelse Staatshoof in 1975.

Uniforms of the bodyguards of the British head of state in 1975.

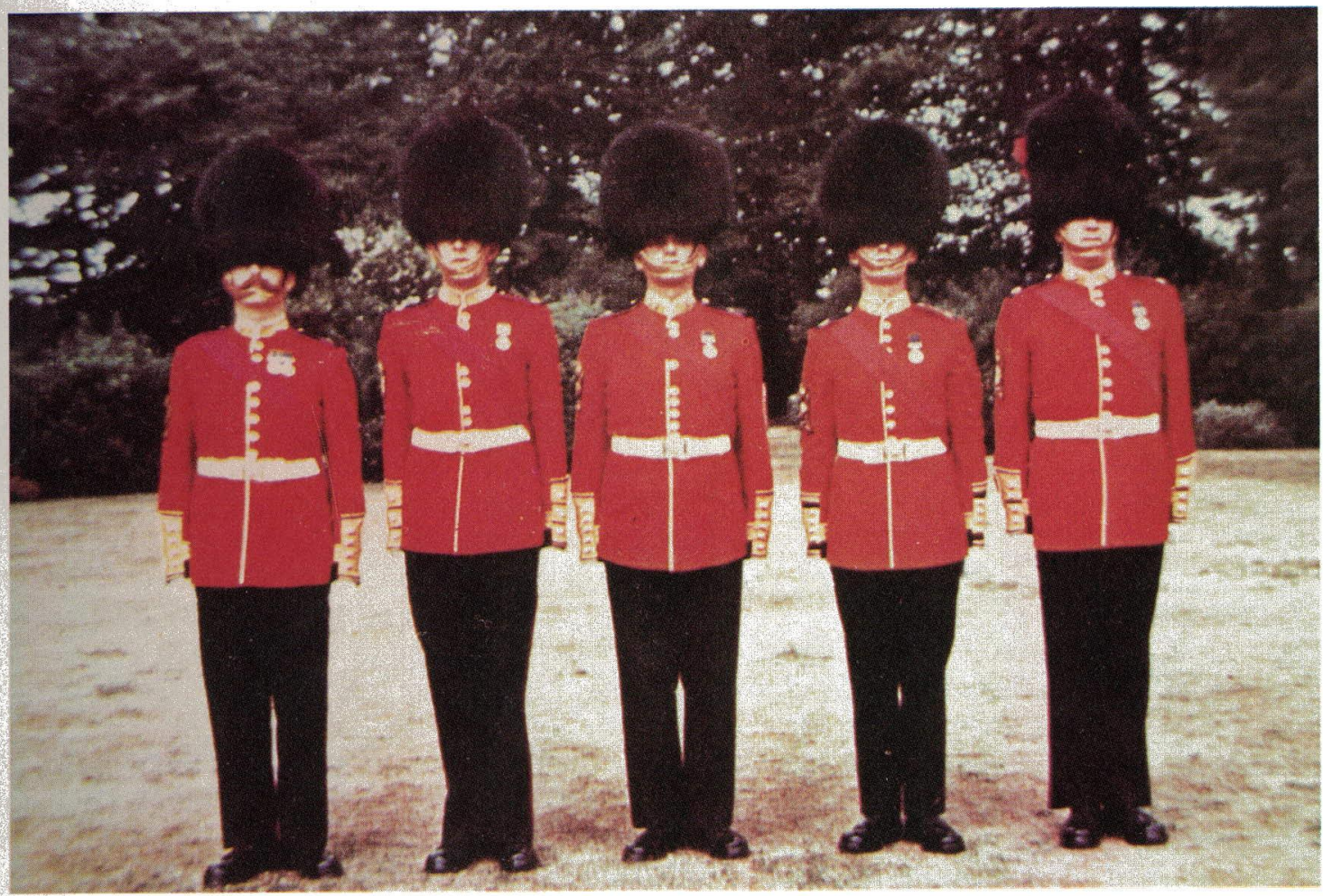




\section{Die Serjeants-at-Arms - Engeland}

In navolging van die Franse voorbeeld het die Engelse koning Richard I, sy persoonlike wag die "Serjeants-at-Arms" genoem. Hulle taak was om ten volle gewapen met swaard en staf sy tent te bewaak. Teen die einde van die 13de eeu was die "Serjeants-at-Arms" gevestigde offisiere in die koninklike huishouding.

\section{Funksies en Pligte}

Die funksie van die koninklike wag was vroeg reeds om die kamp en die koninklike hof te bewaak, die koning teen persoonlike aanvalle te beskerm en as lyfwag op die slagveld. Lede van die wag moes weerskante loop van die offisier wat die koning se swaard dra. Die wag se hooftaak was egter om verdagte persone summier te arresteer.

Van die koninklike wag is verwag om luister te verleen tydens kronings, optogte, feeste en staatsbegrafnisse, om koninklikes en ambassadeurs te begelei ten tye van adresse aan die troon, sowel as die uitvoer van daaglikse pligte in en om die paleis.

\section{Gentlemen-Pensioners}

In 1509 is ' $n$ order gepubliseer wat die vorming van 'n nuwe wag, gekies uit manne van adellike bloed, geproklameer het. Koning Hendrik VIII wou homself hiermee soortgelyk aan die Franse hof, omring met manne van ' $n$ hoë stand en met 'n goeie sosiale posisie. Die wedywering tussen die Franse en Engelse howe het Hendrik genoop om die Franse model nie net na te aap nie, maar te oortref in die samestelling van sy lyfwag.

Vir die eerste 150 jaar van sy bestaan was hierdie groep die enigste Staandemag in Engeland. Die titel Gentlemen-Pensioners wat vanaf 1509 dateer, is vir meer as 300 jaar behou. Later het hulle die benaming "Gentlemen-of-the Axe" aangeneem wat soos hul Franse eweknie op 'n onderskeidende wapen gedui het.

\section{Toelatingsvereistes tot die Koningswagte}

Die belangrikste vereiste in Engeland sowel as Frankryk om tot die wag toegelaat te word, was dat lede van blou bloed moes wees. Offisiere van beide lande het dieselfde bevelstitels gedra. Die hoeveelheid lyfbediendes, perde asook die soort wapens van beide groepe was identies en moes deur lede self voorsien word. Net lede wat deur dapperheid of goeie gedrag hulself in oorloë onderskei het, kon as offisiere van die wag aangestel word.

In 1862 is die korps gereorganiseer en vereistes is so verander dat almal wat sedert die datum aangestel is, kommissie in die leër of marines moes hê en nie ouer as 50 moes wees nie. Elke lid is deur die vors self gekeur en moes aktief op die slagveld gewees het en reeds in besit van 'n dekorasie gewees het.

\section{Bevelvoerder}

Sedert die instelling van die korps was die bevelvoerder van die Wag iemand wat homself onderskei het. Hy was dikwels 'n bloedverwant of aangetroude familie van die koning. Die houers van die eksklusiewe pos was meesal ridders en was dikwels self die kanselier. By sy aanstelling het hy 'n staf ontvang wat by sy uittrede aan sy opvolger oorgedra is.

\section{Uniform variasies en veranderinge daarvan}

Met die instelling van die wag was die materiaal van die uniform van goud en silwer en in 1554 met die val van Boulogne het hulle rooi en geel damas klere gedra. Op hierdie stadium was die eenheid nie net 'n leerskool vir krygsmanne nie maar soldate en staatsmanne is ook deur hulle opgelei.

Tydens Eduard VI se regeringstyd het die wag swart en wit uniforms gedra wat later verander het na die Tudor kleure van groen en wit. Nog was dit nie die einde van die verandering in hul uniform nie want in Elizabeth I se regeringstyd het sy hulle in sober swart mantels met geplooide krae en lang goue kettings geklee. Sy het net diegene aangestel wat vir haar persoonlik aanvaarbaar was.

Koning George IV op sy beurt het op eie koste 'n nuwe uniform aan die wag gegee wat hulle veel spoggeriger laat vertoon het. Die uniform was rooi met blou en goue knope wat soos kant oor die uniform versprei is, rooi sykouse, wit skoene met wit en rooi rose daarop en wit handskoene. Om die uniform af te rond het lede van die wag 'n swart hoed met rooi en swart pluime gedra.

In 1839 verander hulle uniform na 'n mantel, wit belt en helmet en in 1892 verander die uniform weer na die van 'n kavallerie offisier uit die vroeë Victoriaanse era. Tot op hede word die paleis in 
Engeland bewaak, beskerm en verfraai deur 'n korps spesiale wagte. Die seremonie van die verandering van wag bly steeds aanskoulik.

\section{Siam se Vrouewag}

Nog ' $n$ koningswag wat spesiale vermelding verdien, juis omdat dit so anders as die gebruiklike is, is die wag van die koning van Siam. Sedert die begin van die 19de eeu het die koning van Siam 'n uitgesoekte korps vrouesoldate as persoonlike wag aangehou. Hierdie gedugte wag het tot aan die einde van die eeu voortbestaan.

Die eenheid het bestaan uit vierhonderd vroue wat uit die mooiste en sterkste meisies in die land gekies is. Hulle het goeie betaling ontvang en was volmaak gedissiplineerd. Lede van hierdie keurkorps moes tussen 13 en 25 jaar oud wees.

Hul uniform het bestaan uit spoggerige wit rokke wat met goud geborduur is. 'n Ligte gepantserde jas en 'n vergulde borsharnas het die rok bedek, hoewel hulle arms vry was. Die kop was met ' $n$ vergulde helm bedek. Tydens staatsfunksies het die vroue seremoniële drag gedra en was hulle met ' $n$ lans gewapen. Wanneer hulle in gevegstenue geklee was, het hulle 'n geweer gedra.

Die battaljon het uit vier kompanies van een honderd vroue elk bestaan en is deur ' $n$ kaptein aangevoer. In die loop van sy bestaan het die koning geen ekspedisie sonder hulle onderneem nie. Elke vrou het vyf bediendes in haar diens gehad.

Vir hul prestasies het die vroue pleks van dekorasies, juwele ontvang. Die vroue is nie in die geveg gebruik nie, maar wel om die koning te beskerm as hy in 'n gevaarlike situasie sou wees.

\section{Switserse Wag in die Vatikaanstad}

Die wêreld se kleinste staat, die Vatikaanstad van wie die Pous, heerser van die Katolieke Kerk, die Staatshoof is, word deur 'n spesiale seremoniële eenheid die Switserse Wag, bewaak en beskerm. Hierdie tradisie bestaan al meer as vier eeue lank.

Die Switserse Wag is 'n militêre eenheid wat sedert sy totstandkoming in 1506 die beskerming van die persoon van die Pous sowel as die bewaking van die Vatikaanstad as hooftaak het. Die Wag vergesel die Pous op sy oorsese reise en is ook belas met honorêre pligte wanneer buitelandse staatslui en ambassadeurs verwelkom word. Op sulke geleenthede dra die Wag hul seremoniële blou, rooi en geel uniform.

In die eerste helfte van die $17 \mathrm{de}$ eeu het die beskerming van Pous Clement VII en die verdediging van die Vatikaanstad teen 'n mag van 2000 invallende Duitse en Spaanse huursoldate, die Wag 'n verlies aan 189 lewens gekos. Sedertdien was die Switserse Wag nie in enige soortgelyke aksie betrokke nie, hoewel hulle die Pous getrou bygestaan het.

Lidmaatskap van die Switserse Wag, wat tans uit meer as 100 inwonende lede bestaan, is eksklusief en streng vereistes word aan voornemende rekrute gestel. 'n Lid moet 'n ongetroude Switserse katoliek wees, 'n onbesproke karakter hê, 1,74 meter lank wees, onder 30 jaar oud wees en sy basiese opleiding reeds in Switserland voltooi het. Daar word van elke lid verwag om 'n dienstydperk van ten minste 2 jaar te doen. Lede van die Wag praat oor die algemeen nie net Duits, Frans en Engels nie, maar word verplig om Italiaanse lesse te neem solank hulle in Rome is.

\section{Slot}

Suid-Afrika self spog met ' $n$ militêre eenheid, die Staatspresidentseenheid, beter bekend onder die vroeëre benaming van Staatspresidentswag, wat die beskerming van die staatshoof as primêre funksie het. Soos die geval met genoemde Engelse, Franse en Switserse eenhede het die Suid-Afrikaanse Staatspresidentseenheid ook 'n roemryke verlede. Die SP eenheid se herkoms dateer uit die dae van die artillerie-eenhede wat deur die twee Boererepublieke op die been gebring is.

\footnotetext{
* Lt kdr EM Meyers MA (HOD) is verbonde aan die Militêre Informasieburo, SAW
}

\section{Bibliografie:}

1. Brackenbury $H$ : The Nearest Guard: A history of Her Majesty's Body Guard of the Honourable Corps of Gentlemen-at-Arms, Harrison and Sons, London, 1892.

2. Laffin J: Women in Battle, Abelard Schuman, London, 1967.

3. Smith Graham: Guards of the Smallest State, Soldier, Vol 39/17. September 1893.

4. Die Staatspresidentswag 10 Jaar, SA Vlootdrukpers. 